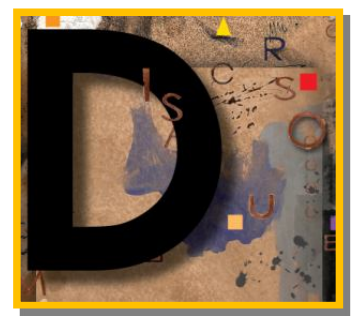

\title{
A ANÁLISE DE DISCURSO CRÍTICA EM APOIO À GESTÃo ORGANIZACIONAL
}

DISCURSOS CONTEMPORÂNEOS

EM

ESTUDO

ISSN 2237-7247

\author{
Valério Brusamolin ${ }^{1}$ (UniCeub)
}

O presente artigo tem por propósito investigar a aplicabilidade da análise crítica do discurso na gestão organizacional. Para tanto, revisaram-se os documentos indexados na base de dados Proquest com os argumentos "critical analysis discourse" e "management", por meio do que se obtiveram nove artigos e duas teses, de cuja análise se sintetizaram os seguintes usos do discurso na gestão: gerenciamento de mudanças, construção de significado, gestão organizacional, gestão do conhecimento, construção de contexto, metodologia para pesquisas em gerenciamento estratégico, liderança, análise do discurso gerencial e gestão de recursos humanos. Dada a comprovação de que o discurso possui importância na gestão de mudanças e posto que o objetivo da gestão da informação é o aprendizado, este artigo propõe um processo de gestão informacional para discursos.

Palavras-chave: Análise de Discurso Crítica. Análise de Discurso. Gestão da Informação. Memória Organizacional. Gestão do Conhecimento.

This paper aims to investigate the applicability of critical discourse analysis in the organizational management. For that, a review in the indexed documents of Proquest database was made, achieving nine articles and two doctoral thesis, from which analysis the following uses of discourse in management were obtained: change management, sense making, organizational management, knowledge management, context building, research methodology for strategic management and human resources management. Established the importance that discourse has at change management, and considering that the objective of information management is learning, this article proposes a process for discoursive information management.

Keywods: Critical Discourse Analysis. Discourse Analysis. Information Management. Organizational Memory. Knowledge Management.

${ }^{1}$ Doutor em Ciência da Informação pela Universidade de Brasília; mestre em Gestão do Conhecimento e da Tecnologia da Informação pela Universidade Católica de Brasília (UCB). E-mail: brusamolin@ gmail.com. 


\section{Introdução}

Segundo Fairclough (2001, p. 19-20), a Linguística está associada a processos de mudança social e cultural, fenômenos de interesse de uma ampla variedade de disciplinas. Além disso, dados linguísticos como entrevistas são amplamente utilizados em ciências sociais. Como as fronteiras entre essas ciências estão se enfraquecendo, não é de se estranhar que esteja se conferindo à linguagem um papel mais central no estudo dos fenômenos sociais. Nesse sentido, a Análise do Discurso é, atualmente, a área da Linguística para estudos de linguagem envolvendo o pensamento social e político presentes no ambiente organizacional.

Procurando por evidências da afirmação de Fairclough na literatura gerencial, é possível encontrar vários autores se aprofundando em aspectos da linguagem. Para Echeverría (1997, p. 264), o papel do gerente é essencialmente conversacional: seu trabalho consiste fundamentalmente e quase exclusivamente em participar de conversações (ou discursos), promover algumas conversas e evitar outras. Para Denning (2005, p. 20), não apenas para o gerente, mas para a maioria das pessoas na economia do conhecimento, conversa (discurso) é trabalho. Quando alguém aprende a conversar (discursar) de forma mais efetiva, pode se tornar muito mais produtiva. Kofman (2005), por sua vez, elaborou uma metodologia para gestão que, utilizando linguagem e emocionalidade, tem por propósito um melhor relacionamento entre as pessoas dentro das organizações.

O ambiente organizacional tem, portanto, passado por transformações ambientais que desafiam paradigmas estabelecidos de comando e controle. O pressuposto de que os gerentes possuem todo o conhecimento e poder de mando, aos demais cabendo apenas a execução de planos e ordens não serve às organizações modernas. $O$ papel de capataz do gerente tornou-se inadequado ao trabalho do conhecimento. Hoje, o novo gerente deve ser um líder de líderes, um sedutor que possui habilidades conversacionais, capaz de obter um alto desempenho de sua equipe estimulando conexões entre os integrantes (ECHEVERRÍA, 2004). Assim, a gestão do conhecimento vem ganhando espaço nesse ambiente complexo, ensinando que seres humanos são mais importantes que equipamentos e destacando que a narrativa, um tipo de discurso em especial, é uma técnica útil para diversos propósitos gerenciais (BRUSAMOLIN, 2008; CAMILLE \& WILLIAN, 2004; DENNING, 2005).

A Linguística, por sua vez, parece estar se libertando do isolamento decorrente de paradigmas formalistas e cognitivos e se interessando pelo pragmatismo (FAIRCLOUGH, 2001, p. 19). Estudos de gestão seguem uma abordagem pragmática, isto é, preocupam-se com a compreensão da ação humana e suas consequências. Nesse sentido, Phillips (2008) identificou um crescente número de artigos publicados em periódicos de gerenciamento e negócios que 
incluem Análise de Discurso Crítica (ADC) no corpo do texto, uma evidência de que essa área do conhecimento esteja se popularizando em estudos organizacionais e gerenciais. Em outro artigo, esse mesmo autor (2004) argumenta que a organização é construída pelo discurso e propõe um modelo de relacionamento entre este, a instituição e a ação. Treleaven e Sykes (2005), por sua vez, investigam a perda de conhecimento decorrente da estrutura de poder que legitima e marginaliza discursos em uma organização. Francis (2006), finalmente, investiga o emprego da ADC na concepção de novas práticas gerenciais.

Dada a relevância que o discurso possui na construção e gerenciamento de uma instituição, o presente artigo visa identificar as aplicações da ADC na gestão organizacional. Para tanto, são observados especialmente aspectos referentes à gestão da informação e do conhecimento, levantando-se subsídios para a proposição de um modelo de gestão informacional para discursos.

\section{Referencial Teórico}

\section{Análise de Discurso Crítica}

A Análise de Discurso Crítica (ADC) foi desenvolvida por Norman Fairclough e propõe uma abordagem metodológica que analisa o discurso sob três aspectos ou dimensões: prática social, prática discursiva e texto (FAIRCLOUGH, 2001, p. 100-101). Tem por propósito explicitar as relações de poder, as ideologias e os efeitos construtivos que o discurso exerce sobre as identidades sociais, as relações sociais e os sistemas de conhecimento e crença (FAIRCLOUGH, 2001, p. 31).

A Figura 1 ilustra essa concepção da ADC. A prática social tenta compreender o contexto social em que se dá o discurso; é "alguma coisa que as pessoas produzem ativamente e entendem com base em procedimentos de senso comum compartilhados"; é um esforço para tentar entender como o integrantes de comunidades sociais produzem seus mundos "ordenados" e “explicáveis". A prática discursiva, por sua vez, envolve os processos de produção, distribuição e consumo textual. Finalmente, a dimensão do texto se preocupa com quatro fatores: vocabulário, gramática, coesão e estrutura textual (FAIRCLOUGH, 2001, p. 100-106). 


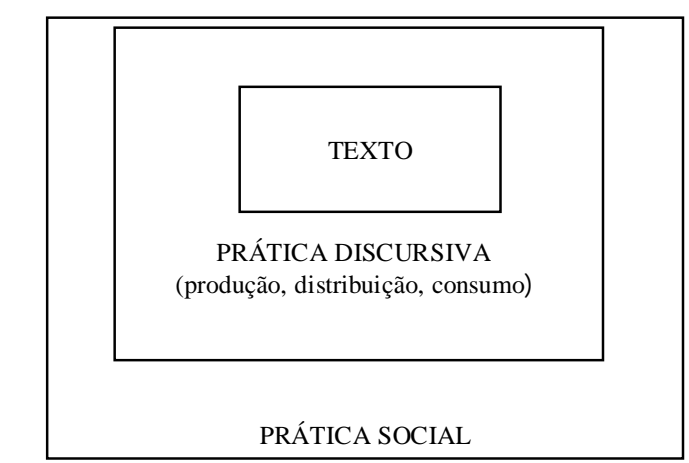

Figura 1 - Concepção tridimensional do discurso (FAIRCLOUGH, 2001, p. 101)

\section{Narrativas, Gestão do Conhecimento e Discurso}

A gestão do conhecimento teve início com trabalhos de informáticos, que tratavam o conhecimento como um produto que poderia ser "capturado", armazenado e compartilhado. Posteriormente, estabeleceu-se a convicção de que não poderia existir conhecimento sem conhecedor, ou seja, quem conhece são pessoas; conhecimento não é produto e pessoas são mais importantes do que equipamentos. Mais importante do que a habilidade em lidar com computadores e outras máquinas, passou a ser a habilidade de interagir com seres humanos, o que se faz, também, por meio conversas.

O trabalhador do conhecimento tem de interagir com pessoas. Segundo literatura de gestão do conhecimento, a técnica de narrativas é uma forma eficaz de comunicação. Narrativas, sob a perspectiva da gestão do conhecimento, são relatos de um ou mais eventos, verdadeiros ou fictícios, realizados com algum propósito útil à organização. A diferença entre uma narrativa e a citação de um exemplo está na adição de conteúdo emocional e detalhes sensoriais na primeira. Uma narrativa, portanto, mescla detalhes, personagens e eventos em um todo que é maior do que a soma das partes (SIMMONS, 2001, p. 31) e ela pode ser tão curta como uma simples frase (GARGIULO, 2005, p. 10).

Dessa forma, a narrativa é um instrumento útil ao gerente que, por vezes, possui formação puramente técnica - computacional ou matemática. Logo, uma orientação sobre como interagir com pessoas lhe é valiosa. Gerentes bem-sucedidos empregam narrativas de forma intuitiva para estimular a colaboração, motivar a equipe e transferir conhecimento (BRUSAMOLIN, 2008). Além desses, diversos outros propósitos podem ser identificados na literatura, como por exemplo: exemplificar a cultura organizacional, modificar e controlar comportamentos, resolver problemas, tomar decisões, gerenciar mudanças, planejar 
estrategicamente, melhorar a imagem do líder, treinar futuros líderes, transmitir uma visão de futuro e silenciar rumores (CAMILLE \& WILLIAN, 2004; DENNING, 2005).

Para a Linguística, narrativa é um tipo particular de discurso, aquele que descreve uma série de eventos relacionados lógica e cronologicamente (FAIRCLOUGH, 2003, p. 83). Discurso é, por sua vez, um uso da linguagem. Para Fairclough, ele é uma prática social, um uso contextualizado da linguagem, uma vez que não faz sentido discursar para si mesmo. É "um modo de ação, uma forma em que as pessoas podem agir sobre o mundo e especialmente sobre os outros, como também um modo de representação" (FAIRCLOGH, 2001, p. 91-92).

\section{Gestão da Informação}

Gestão da Informação é o conjunto das tarefas que suportam as atividades de aprendizagem organizacional (CHOO, 1995). Tais processos devem enfocar os contextos sociais e situacionais do uso da informação, pois o significado e o propósito da informação são dados pelo compartilhamento de energia mental e afetiva entre pessoas envolvidas na solução de problemas ou na construção de significados para situações obscuras.

O resultado de um processo de aprendizagem é a mudança. Quando se fala em aprendizagem organizacional, fala-se em mudança, um aspecto estudado pela Análise do Discurso. Portanto, a Gestão da Informação se realiza em função da necessidade de mudança ou de aprendizagem. Como a literatura científica apresenta evidências de que as narrativas e, por extensão, os discursos, possuem um papel importante no aprendizado organizacional, é possível deduzir que discursos devem constar do ciclo informacional de uma organização.

Registro é o ato que produz um documento, "termo genérico que designa os objetos portadores de informação" (LE COADIC, 2004, p. 5). É o ato que inscreve um conhecimento em um suporte, na forma escrita (impressa ou digital), oral ou audiovisual, gerando a informação, que é o "conhecimento registrado" (LE COADIC, 2004, p. 4).

A Figura 2 ilustra as sete tarefas no Gerenciamento da Informação identificadas por McGee e Prusak (1994, p.108): a) identificação de necessidades e requisitos da informação; b) coleta/entrada de informação; c) classificação e armazenamento de informação; d) tratamento e apresentação da informação; e) desenvolvimento de produtos e serviços de informação; f) distribuição e disseminação de informação; e g) análise e uso da informação. 


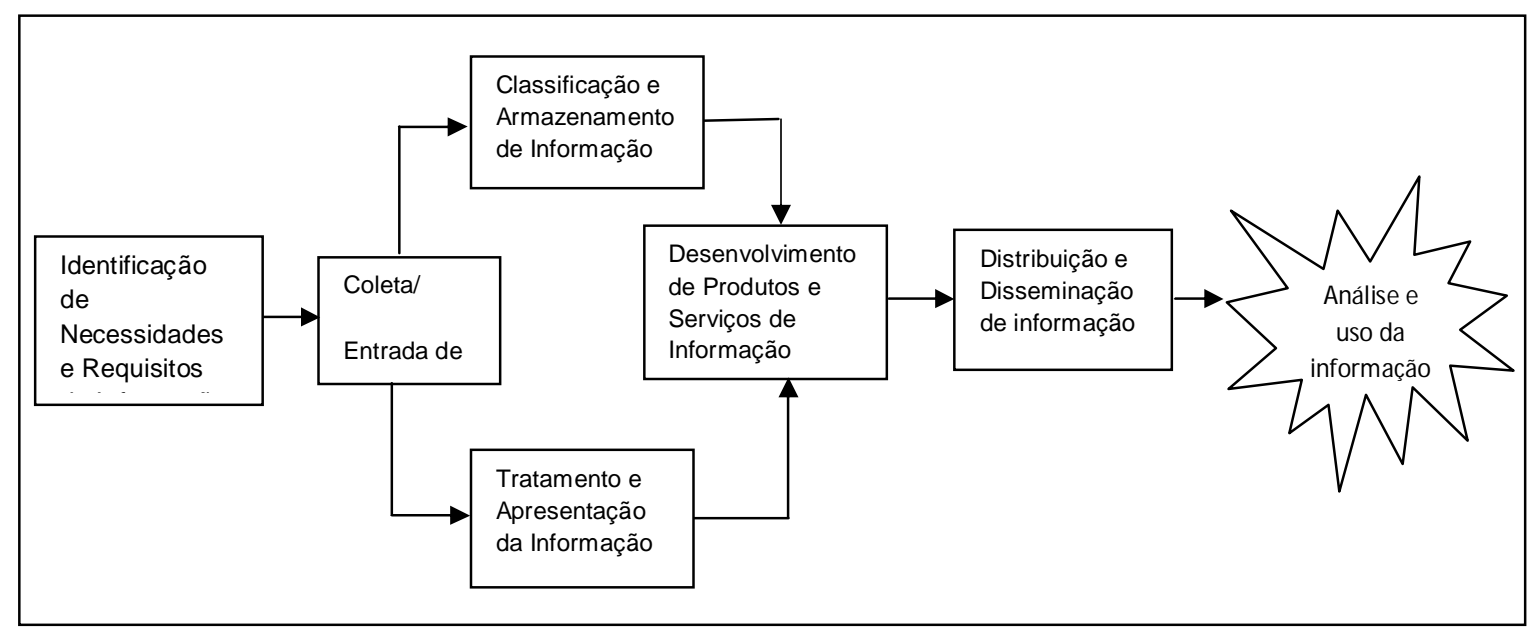

Figura 2 - Tarefas do Processo de Gerenciamento da Informação (McGEE; PRUSAK, 1994, p. 108)

\section{Memória Organizacional}

A noção de memória organizacional possui origem na Sociologia, para a qual a mente coletiva é composta pelas mentes individuais que compartilham informação por meio da troca de símbolos. A memória coletiva, portanto, refere-se aos processos sociais de articulação e comunicação da informação, o que leva a interpretações compartilhadas que são estabelecidas como normas sociais e costumes (STEIN, 1995, p. 19). Dessa formulação surge o conceito de memória organizacional, que é a memória de um grupo social em particular: a organização. Essa construção coletiva se distingue da memória dos indivíduos, pois procedimentos e artefatos organizacionais mantêm o comportamento mesmo quando as pessoas migram ou não possuem mais a memória das experiências que originaram as rotinas (MOORMAN; MINER, 1997 apud PARK; BUNN, 2003).

Com base nessa origem sociológica, várias outras definições de memória organizacional surgiram, como por exemplo:

- Informação armazenada sobre um estímulo de decisão e resposta que, quando recuperada, influencia as decisões do presente (WALSH; UNGSON, 1991 apud PARK; BUNN 2003).

- Repositório para descobertas coletivas, armazenando políticas, procedimentos, rotinas e regras que podem ser recuperados quando necessário (DAY, 1994 apud PARK; BUNN, 2003).

- Conhecimento coletivo de uma organização. Contém as teorias em uso, modelos mentais compartilhados, bases de dados de informações, procedimentos e rotinas formalizados e tradições culturais que guiam comportamentos (SLATER; NARVER, 1995). 
- Crenças coletivas, rotinas comportamentais ou artefatos físicos que variam em seu contexto, nível, dispersão e acessibilidade (MOORMAN; MINER, 1997).

- Formas aprendidas de pensar e agir (MOORMAN; MINER, 1998).

- Informação e conhecimento conhecidos pela organização e os processos pelos quais tais informações são adquiridas, armazenadas e recuperadas pelos membros da organização (ANAND, 1998 apud PARK; BUNN, 2003).

- Armazenamento, organização e recuperação do conhecimento organizacional (CHOU, 2005).

A memória organizacional facilita a aprendizagem, na medida em que repositórios para as informações e conhecimentos que a organização adquiriu proporcionam o contexto e o fundamento para a criação e aplicação de conhecimentos pelas diversas equipes (CHOU, 2005). As informações armazenadas servem de insumo à produção de novos conhecimentos, que, por sua vez, também devem ser armazenados na memória organizacional. Sem ela, o aprendizado teria uma vida relativamente curta, pois as pessoas mudam de firma ou se esquecem de suas regras e funcionamento com o passar do tempo (LEVITT; MARCH, 1988; SINKULA, 1994 apud SLATER; NARVER, 1995). Por isso, Slater e Narver (1995, p. 65) recomendam que o conhecimento seja externalizado, na forma de histórias, de procedimentos operacionais, de declarações de missão e rotinas, para permitir a persistência da memória. Quanto mais volátil o fluxo da mão de obra, mais importante essa tarefa.

\section{Metodologia}

Foi feita uma revisão nas fontes retornadas pela base de dados Proquest (www.proquest.com), que indexa artigos, teses e dissertações. Com os argumentos "critical discourse analysis" e "management" interconectados com o operador lógico "and", a pesquisa listou 31 instâncias, das quais foram selecionados nove artigos e duas teses, que, com base na avaliação do resumo, empregam a análise crítica do discurso no processo de gestão, mais do que metodologia de pesquisa. Foram selecionados também dois artigos produzidos pelo autor de uma das teses, Phillips (2004; 2008). Essas publicações são recentes. Oito documentos têm data igual ou posterior a 2005. A relativamente pequena quantidade de fontes retornadas é indicativo de oportunidades de pesquisa envolvendo gestão e ADC. 


\section{Resultados}

\section{Discurso no Apoio à Gestão}

Phillips (1995) elaborou tese de doutoramento investigando o gerenciamento da legitimidade no ambiente organizacional. É o trabalho mais antigo envolvendo ADC e gestão localizadas. Posterior busca retornou publicações mais recentes do autor sobre o assunto (PHILLIPS, 2004; 2008). Para ele, pode-se considerar que organizações dependem das construções discursivas elaboradas por integrantes envolvendo conjuntos complexos de conceitos para a construção de significado. A ADC seria, nesse contexto, um mecanismo adequado para análise de textos, pois criá-los e disseminá-los são atos políticos, constituem luta pelo poder na organização que procura determinar a natureza dos conceitos, subjugar posições e controlar como os objetos são compreendidos e tratados (PHILLIPS, 2008).

Baseando-se no modelo tridimensional de Fairclough (vide Figura 1), Phillips (2008) propõe um modelo também tridimensional para gerenciamento estratégico de mudanças. $\mathrm{Na}$ dimensão de prática social, este modelo aborda o significado na dimensão da prática discursiva, trata da verdade e de seus efeitos. Ainda nesta dimensão, é trabalhado o "significado", levandose em conta que existem discurso ou narrativas fora da organização que podem ser invocados para apoiar a produção de corpus de conhecimento e sistemas de "verdade" dentro da organização. Na dimensão do texto, avaliam-se os textos ou as conversas. Finalmente, na dimensão da prática discursiva, constroem-se a verdade e seus efeitos.

Num primeiro momento, devem ser desenvolvidos discursos internos que fomentem a mudança estratégica com base em discursos externos, conforme os seguintes propósitos:

- esboçar as possibilidades para "ser" e atuar na organização;

- construir posturas temáticas novas ou modificadas, associando-as a identidades idealizadas;

- utilizar essas posturas temáticas para apoiar atores na organização, ao estabelecer o critério pelo qual uma conduta é julgada correta.

Ainda na dimensão da prática discursiva, num segundo momento, os atores se engajam nas posturas temáticas em qualquer arranjo composto pelas seguintes situações: 
- aceitação: identidades preexistentes são rejeitadas e substituídas por meio da ratificação de novas identidades, levando ao estabelecimento de novas práticas de acordo com o novo discurso;

- apropriação ou resistência velada: as novas identidades são mescladas com identidades preexistentes, formando uma forma híbrida e levando a modificações das práticas existentes, de modo que ficam parcialmente de acordo com o novo discurso;

- resistência explícita: as novas identidades, construídas ou modificadas, são rejeitadas. Estabelecem-se identidades alternativas, que podem ser as pré-existentes ou mesmo outras diferentes. Essa situação impede a modificação ou estabelece outras que não estão de acordo com o discurso de mudança.

Num terceiro momento, os discursos internos podem, eventualmente, apoiar discursos externos. Na dimensão do texto, avaliam-se textos e conversas produzidos pelos membros da organização em resposta aos efeitos do discurso. Ambos podem ser classificados em:

- Narrativas Autoritárias: textos e conversas produzidos em apoio à mudança estratégica e reproduzidos por membros da organização. São produtos da aceitação.

- Narrativas Irônicas: textos e conversas desenvolvidos por membros da organização, usando recursos retóricos tais quais ironia e cinismo para modificar narrativas autoritárias ou, veladamente, desafiá-las. São produtos da resistência velada.

- Contranarrativas: textos e conversas produzidos por membros da organização que abertamente desafiam as narrativas autoritárias. São produtos da resistência explícita.

O modelo de gerenciamento estratégico de mudanças é uma aplicação interessante da teoria crítica do discurso na gestão. Observe-se a importância da informação no modelo, que começa com a informação dos discursos externos à organização, para que sejam utilizados como modelos na elaboração dos discursos internos. Phillips relata a dificuldade de se levantar as narrativas irônicas e também as contranarrativas, pois elas circulam pela organização de boca em boca e nem sempre chegam aos ouvidos dos gestores ou dos pesquisadores. Essa classificação é útil, portanto, para análise das narrativas organizacionais e também para classificação das narrativas que sejam armazenadas na memória organizacional.

Em outro trabalho, Phillips (2004) apresenta um modelo discursivo para a institucionalização de práticas, argumentando que instituições são constituídas pelo conjunto estruturado de seus textos, os quais produzem categorias sociais e normas que formam os 
entendimentos e os comportamentos dos atores. Além disso, quase tudo o que se sabe sobre uma organização provém de textos tais como organogramas, relatórios, conversações, histórias e outros gêneros.

A Figura 3 demonstra o relacionamento entre ação e discurso. A ação influencia o discurso por meio da produção de textos. Somente ações que produzem textos possuem o potencial de influenciar discursos. Tais textos podem ser desde descrições conversacionais entre colegas de trabalho até textos mais elaborados e mais amplamente distribuídos, como manuais. $\mathrm{O}$ discurso, por sua vez, provê o mecanismo que institucionaliza ou reprime as práticas e molda as ações que produzirão mais textos e assim por diante, num ciclo repetitivo e sem fim.

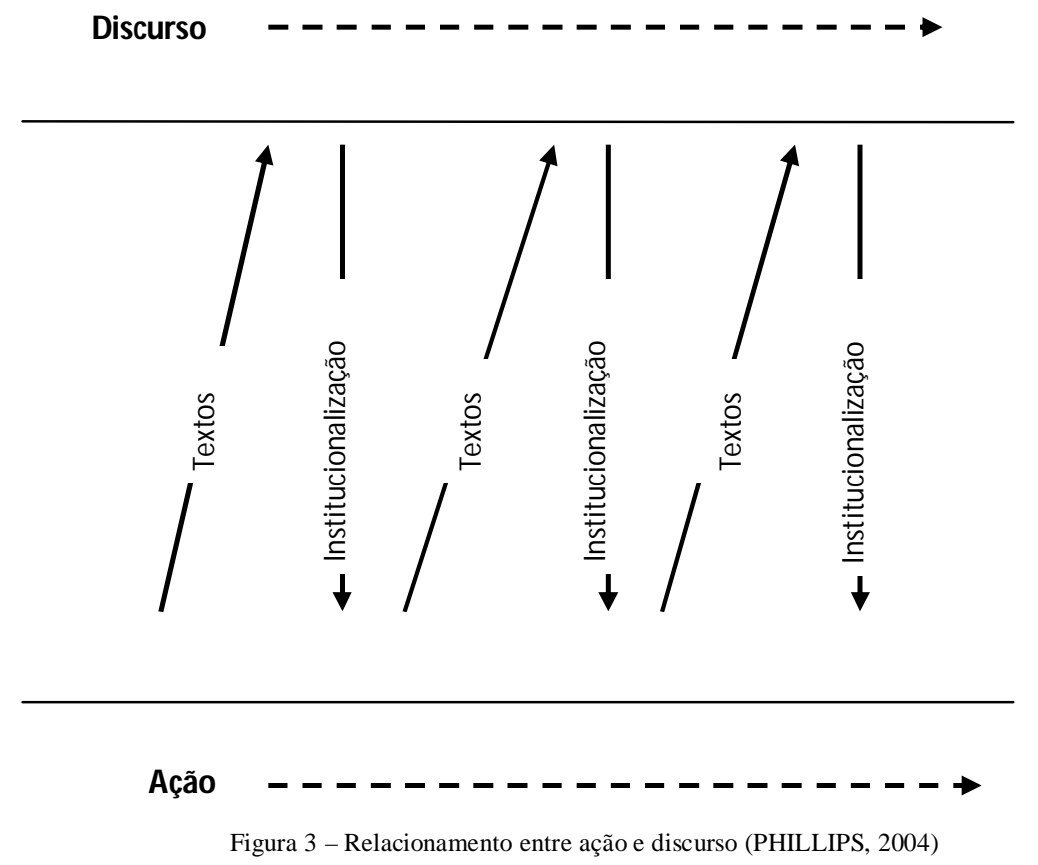

Analisando-se o relacionamento entre ação e discurso, pode-se perceber a importância da inserção das narrativas no ciclo informacional, facilitando a sua recuperação para a atuação gerencial na elaboração dos discursos que moldarão os processos organizacionais. Se as narrativas permanecem apenas nas conversas entre trabalhadores, faltará informação para um bom discurso ou narrativa dos gestores. Se o discurso ou narrativa dos gestores por outro lado não for disseminado pela organização, o efeito desejado na ação pode ter impacto reduzido. Como destacam Taylor e Van Every ${ }^{2}$ (apud PHILLIPS, 2004), um texto que não é lido, citado ou usado, ainda não é um texto.

A Figura 4 ilustra o modelo discursivo de institucionalização. A base constitui outra representação da mesma semântica desenhada na Figura 2: ações geram textos, que são

\footnotetext{
${ }^{2}$ Para saber mais, ver: TAYLOR, J. R.; VAN EVERY, E. J. The emergent organization: communication as its site and service. Mahwah, NJ, Lawrence Erlbaum Associates, 2000, p. 292.
} 
encaixados em discursos que produzem instituições, que, por sua vez, restringem ou habilitam ações.

Os textos são gerados com o propósito de construir significados ou prover legitimidade a um determinado ator. Ações que são novas ou inesperadas demandam trabalho expressivo na construção de significado; é um processo linguístico que envolve narrativas, pois os gerentes podem facilitar o entendimento de novas práticas ao narrarem continuamente histórias que ilustrem a realidade da nova prática (PFEFFER ${ }^{3}$ apud PHILLIPS, 2004). A legitimidade é necessária para justificar a ocupação de um determinado território pela organização. Legitimação é um processo de construção social das explicações e justificativas da existência da instituição.

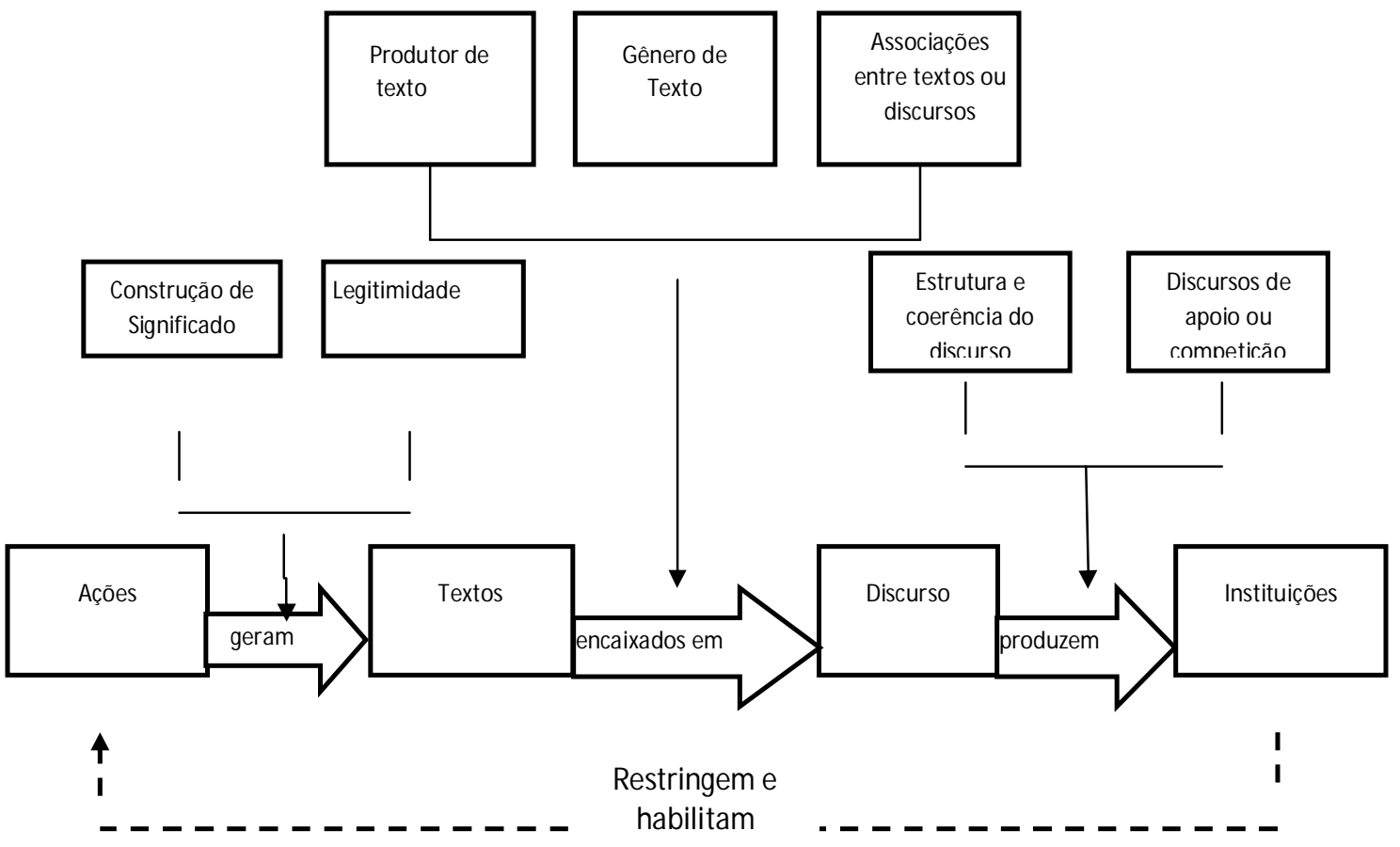

Figura 4 - Modelo Discursivo de Institucionalização (PHILLIPS, 2004)

A adoção de uma estrutura já em prática na organização facilita a sua compreensão. Fairclough (1995) ensina que existem infinitas possibilidades de estruturas textuais ou discursivas, de modo que não há uma estrutura genérica. Entretanto, experiência do autor desse artigo realizada no Instituto Brasileiro de Informação em Ciência e Tecnologia (Ibict) evidenciou que, para alguns atores, um padrão facilita a elaboração de narrativas coerentes e compreensíveis. No caso do Ibict, foi adotada a estrutura obtida pela integração de cinco questões padrões do jornalismo (SILLINCE, 2007): Quem? O que? Quando? Onde? Por quê? Essa sequência de perguntas propicia os elementos básicos de uma narrativa, que pode ser ainda aperfeiçoada com detalhes sensoriais que arremetam para diversos sentidos (tato, paladar, olfato,

\footnotetext{
${ }^{3}$ Para saber mais, ver: PFEFFER, J. Power in organizations. Marshfield, MA, Pitman, 1981, p. 23.
} 
visão, audição) e a tornem mais interessante, facilitando o seu registro na memória. O discurso que for apoiado por outros discursos produzirá resultados de institucionalização mais consistentes. Por outro lado, a existência de discursos rivais ou competitivos reduz a possibilidade de que ambos produzam resultados.

Quanto ao produtor de texto, são considerados três aspectos: a) discursos consensualmente válidos são proferidos por atores que ocupam posições que lhes garantam voz e lhe conferem legitimidade; b) o produtor do texto pode reforçar o texto com o emprego de meios coercitivos, como autoridade formal ou força política; e c) o produtor pode ser capaz de adicionar textos em discursos simplesmente por causa da sua posição central na rede social da organização, pois pode mais facilmente disseminar seus textos para um número maior de atores.

Phillips (2004) propõe que textos, ao adotarem a forma de gêneros reconhecidos, interpretados e utilizados em outras organizações, terão maior probabilidade de ser encaixados em discursos, pois gêneros são ações sociais significativas realizadas pela linguagem, ou atos de fala; esses atos são realizados por meio de formas textuais padronizadas, típicas e, portanto, inteligíveis (BAZERMAN, 2005, p. 22). Quando gêneros são transformados e preservados em formas textuais, podem prover o ator com fonte útil para a obtenção de textos ou narrativas que possam ser incorporadas nos seus próprios textos ou discursos. Portanto, as narrativas podem ser convertidas em informação pelo registro e armazenamento em um dispositivo, como por exemplo, um banco de dados. Tal procedimento facilita a compreensão da cultura, do contexto institucional e fornece, ao gestor, histórias úteis para a elaboração de seus próprios discursos.

Por que encaixar textos ou discursos de outros no próprio discurso? A associação implícita ou explícita a um discurso ou texto anterior confere legitimidade e força ao discurso ou texto presente (FAIRCLOUGH, 1998, p. 133-138). Quando se trata de vinculação entre textos, denomina-se intertextualidade e, entre discursos, interdiscursividade.

A intertextualidade reforça o discurso, mas pode ocasionar a rigidez organizacional, que seria a incapacidade de mudar e evoluir, presa no contexto criado pela malha de discursos interligados. Sillince (2007) propõe o emprego da ADC na reestruturação do contexto de organizações. Um contexto pode ser flexibilizado por meio de discursos construídos mediante negociação e participação de membros interessados da organização. O autor considera que um discurso que responda as perguntas quem, quando, onde e por quê, está estruturado e é suficiente para definir um contexto. A estrutura facilita o registro e o armazenamento do discurso, permitindo sua distribuição e, consequentemente, entendimento compartilhado do contexto. Aqui, percebe-se a menção das principais atividades de um ciclo de gestão da informação: o registro dos discursos ou narrativas, que permite que elas sejam distribuídas a todos os integrantes da organização, contribuindo para uma visão compartilhada; a atuação de atores que 
reforcem seus discursos pelo interdiscurso e a construção da memória da organização, habilitando o aprendizado. Só se aprende aquilo que se recorda (recupera).

Sillince propõe uma gestão participativa, na qual discurso e contexto são socialmente construídos. A flexibilidade decorrente da permanente reconstrução do contexto é necessária para a organização que pretende sobreviver às constantes mudanças do ambiente externo, sobre o qual não se tem controle. Trata-se de uma proposta de gestão que é mais moderna do que modelos baseados no antigo paradigma de comando e controle e que demonstra como a ADC pode contribuir para mudanças nas concepções de gestão. Hacley (2000) empregou a ADc para analisar aspectos de gerenciamento em uma organização que segue técnicas modernas de gerenciamento: sem comando e controle, sem autoridade ou sanções explícitas. Foi constatada, entretanto, uma espécie de gerenciamento pelo discurso, a qual, por meio de construções discursivas, exercia controle psicológico sobre os integrantes.

Segundo Francis (2006), a ADC é "uma lente poderosa" que pode ser empregada no ambiente organizacional para, ao se analisar discursos, evidenciar conflitos, resistências e cultura. Francis (2006) elaborou estudo de caso de processo de mudança organizacional em que ele analisa discursos de diretores, gerentes e operários envolvidos em um processo de mudança. $\mathrm{O}$ autor conclui que a ADC pode proporcionar descobertas importantes sobre a dinâmica da mudança em uma rede complexa e mutante de alianças de poder e discursos relacionados.

Foi nesse sentido que Harrison e Young (2005) empregaram a ADC para desmascarar estilos e ideologia de líderes envolvidos em um processo de mudança. Foram identificados os conflitos entre os estilos gerenciais do velho e do novo capitalismo. Comando e controle é, portanto, o estilo do líder do velho capitalismo, enquanto o líder do novo capitalismo é apresentado como coach, mentor, facilitador e motivador, não mais como um comandante. Os autores demonstram que mensagens ocultas nos discurso podem contribuir para o fracasso ou o sucesso de discursos e, com isso, comprometer um processo de mudança.

A ideologia do comando e do controle possui forte tradição no ambiente organizacional, provavelmente porque apresentou bons resultados no passado. Entretanto, em organizações em que o conhecimento é o principal fator de produção, comando e controle simplesmente não funcionam. Em organizações de conhecimento, geralmente o subordinado sabe muito mais sobre a tarefa que executa do que o chefe e, se apenas as chefias tiverem poder de voz, o conhecimento não é disseminado e pode até ser perdido, o que aconteceu em um processo de mudança estudado por Treleaven e Sykes (2005), no qual a implantação de um modelo gerencialista neoliberal marginalizou detentores de importantes conhecimentos para a organização.

Thomas (2005), por sua vez, analisa como as ideias gerenciais são desenvolvidas, observando como os textos são recontextualizados desde a academia até a organização. $\mathrm{O}$ autor 
apresenta evidências de que a teoria do discurso pode contribuir com modelos gerenciais em voga, como os de gestão do conhecimento que o tratam como commodity, mas apresentam lacunas nas atividades de produção, distribuição e consumo, aspectos estudados na teoria crítica do discurso.

Uma das tarefas mais importantes em uma organização é a elaboração do planejamento estratégico, que é feito tradicional e intuitivamente de forma discursiva. Vaara elaborou estudo de caso visando compreender melhor o papel do discurso nessa lide. O Quadro 1 resume as fontes analisadas, listando as publicações e usos identificados para a ADC. Gerenciamento de mudanças é o emprego mais frequente: 7 ocorrências (itens a, b, c, d, e, f, k). Construção de significado também é de uso frequente, com 5 ocorrências (itens a, b, c, j, k). Outros usos são: gestão organizacional, gestão do conhecimento, construção de contexto, metodologia para pesquisas em gerenciamento estratégico, liderança, análise do discurso gerencial e gestão de recursos humanos.

\begin{tabular}{|c|c|c|}
\hline Item & Publicação & Usos da ADC \\
\hline $\mathrm{a}$ & $\begin{array}{l}\text { Applying Critical Discourse Analysis in Strategic } \\
\text { Management Research (PHILLIPS, 2008) }\end{array}$ & $\begin{array}{l}\text { - } \text { Metodologia para pesquisas em gerenciamento estratégico } \\
\text { - } \quad \text { Gerenciamento de mudanças } \\
\text { - } \quad \text { Construção de significado } \\
\end{array}$ \\
\hline $\mathrm{b}$ & Discourse and Institutions (PHILLIPS, 2004) & $\begin{array}{l}\text { - } \quad \text { Gerenciamento de mudanças } \\
\text { - } \quad \text { Gestão organizacional } \\
\text { - } \quad \text { Construção de significado }\end{array}$ \\
\hline $\mathrm{c}$ & $\begin{array}{l}\text { Organizational Context and the Discursive Construction of } \\
\text { Organizing (SILLINCE, 2007) }\end{array}$ & $\begin{array}{ll}\text { - } & \text { Gerenciamento de mudanças } \\
\text { - } & \text { Construção de significado } \\
\text { - } & \text { Construção de contexto } \\
\end{array}$ \\
\hline d & $\begin{array}{l}\text { A Critical Discourse Perspective on Managers' Experiences } \\
\text { of HRM (FRANCIS, 2006) }\end{array}$ & $\begin{array}{l}\text { - Gerenciamento de recursos humanos } \\
\text { - Gerenciamento de mudanças }\end{array}$ \\
\hline $\mathrm{e}$ & $\begin{array}{l}\text { Leadership Discourse in Action: a textual study of } \\
\text { organizatinoal change in a government of Canada } \\
\text { department (HARRISON; YOUNG, 2005) }\end{array}$ & $\begin{array}{ll} & \text { Análise do discurso gerencial } \\
\text { - } & \text { Liderança } \\
\text { - } & \text { Gerenciamento de mudanças } \\
\end{array}$ \\
\hline $\mathrm{f}$ & $\begin{array}{l}\text { Loss of Organizational Knowledge: from supporting clients } \\
\text { to serving head office (TRELEAVEN; SYKES, 2005) }\end{array}$ & $\begin{array}{ll}\text { - } & \text { Gerenciamento de mudanças } \\
\text { - } & \text { Gestão do conhecimento } \\
\end{array}$ \\
\hline $\mathrm{g}$ & $\begin{array}{l}\text { The Recontextualization of Management: a discoursive- } \\
\text { based approach to analysing the development of } \\
\text { management thinking (THOMAS, 2003) }\end{array}$ & - Gestão do conhecimento \\
\hline $\mathrm{h}$ & $\begin{array}{l}\text { Strategies as Discoursive Constructions: the case od Airline } \\
\text { Alliances (VAARA et al) }\end{array}$ & - Gerenciamento estratégico \\
\hline $\mathrm{i}$ & $\begin{array}{l}\text { Silent Running: tacit, discursive and psychological aspects } \\
\text { of management in a top UK advertising agency } \\
(\text { HACKLEY, 2000) }\end{array}$ & $\begin{array}{l}\text { - Gestão de recursos humanos } \\
\text { - } \quad \text { Gestão do conhecimento } \\
\end{array}$ \\
\hline $\mathrm{j}$ & $\begin{array}{l}\text { The Management of Corporate Legitimacy: an interpretive } \\
\text { structuralist approach (PHILLIPS, 1995) }\end{array}$ & $\begin{array}{ll} & \text { Gestão organizacional } \\
\text { - } & \text { Construção de significado } \\
\end{array}$ \\
\hline $\mathrm{k}$ & $\begin{array}{l}\text { Meaniingful Change: making sense of the discourse of the } \\
\text { language of change (THURLOW, 2007) }\end{array}$ & $\begin{array}{ll}\text { - } & \text { Gestão de mudanças } \\
\text { - } & \text { Construção de significado }\end{array}$ \\
\hline
\end{tabular}

Quadro 1 - Uso da Análise Crítica do Discurso na Gestão 


\section{O Processo de Gestão Informacional para Discursos}

Como foi dito, a literatura científica apresenta diversas evidências da importância do discurso para a gestão organizacional. $\mathrm{O}$ gerente pode elaborar um melhor discurso se conseguir associá-lo a discursos anteriores; pode reconhecer o contexto com base em discursos passados. A disseminação desse discurso elaborado permite a construção de significados compartilhados. Por isso, a hipótese defendida pelo presente artigo é que a inserção dos discursos no ciclo da informação de uma organização favorece a aprendizagem organizacional.

Uma vez que o resultado de um processo de aprendizagem é a mudança, e que a gestão de mudanças é o principal uso do discurso no ambiente organizacional, conforme constatado na literatura de ACD, provavelmente, o registro dos discursos ou narrativas contribui para o êxito de um processo de mudança. $\mathrm{O}$ registro reconfigura o discurso para algum gênero que possa ser preservado e recuperado, como texto escrito, áudio ou vídeo digitais, fotografia ou desenho. Com a reconfiguração do discurso para um gênero gerenciável, ele pode ser inserido no ciclo informacional da organização e incorporado à memória organizacional, adquirindo a persistência necessária para o aprendizado. Não se aprende aquilo que não pode ser lembrado. Preservando seus discursos, a organização garante que possam ser lembrados e reforçados em novos discursos, conferindo legitimidade e força ao seu processo de mudança.

A Figura 5 ilustra a proposta de um processo de gestão informacional para discursos baseado no processo de autoria de McGee e Prusak (1994, p. 108). O processo inicia-se com a identificação das práticas discursivas da organização, com base em que se pode definir como são configurados os processos de produção, distribuição e consumo textual da organização. Tais processos podem ser, então, monitorados para garantir o registro dos discursos, que, uma vez reconfigurados em um tangível, poderão ser classificados e armazenados conforme índices que facilitem a sua recuperação. $O$ tratamento e a apresentação dos discursos compreendem a atividade de se projetar interfaces de fácil e intuitiva utilização pelos usuários. 


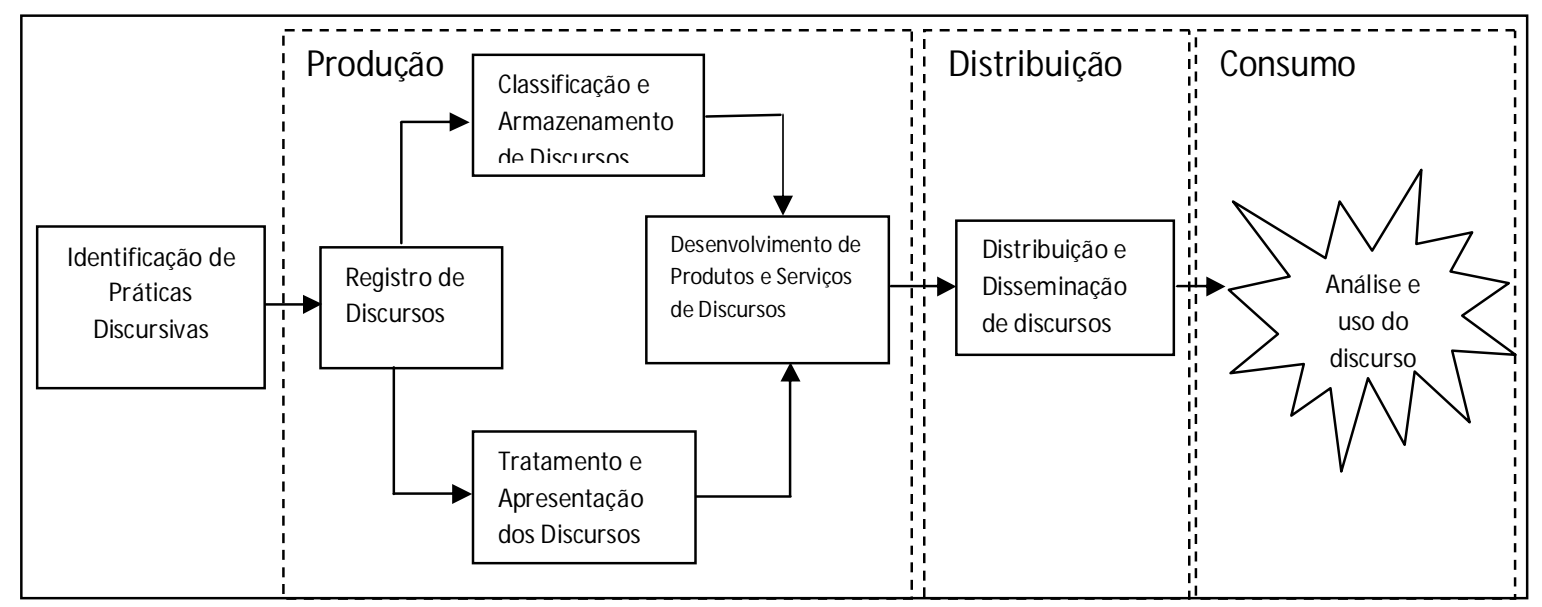

Figura 5 - Processo de Gestão Informacional para Discursos (Adaptado de MCGEE, J.; PRUSAK, L. 1994, p. 108).

Para Taylor $^{4}$ (apud CHOO, 2003, p. 412), produtos e serviços de informação agregam valor à informação, conferindo-lhe um ou mais dos seguintes atributos: facilidade de uso, redução de ruído, qualidade, adaptabilidade, economia de tempo e economia de custo. Um dos produtos que podem ser oferecidos à gestão estratégica da organização são os relatórios críticos de discursos que tragam à tona conflitos, ideias e contextos que permeiam a organização. Outro produto é a identificação de discursos que podem ser distribuídos entre os integrantes da organização para a institucionalização de ações. Também é produto o recurso de recuperação de discursos anteriores.

Distribuição da informação é o processo pelo qual os discursos (informações) são disseminados pela organização (CHOO, 2003, p. 414), promovendo o aprendizado, pois estimula a geração de novas ideias com base na combinação de itens de informação isolados (CHOO, 1995). Portanto, aprendizagem organizacional é positivamente afetada pelo processo de distribuição e disseminação de discursos.

CHOO (2003, p. 415) sugere os seguintes canais para a disseminação da informação: correio eletrônico, discussões online e videoconferências. Os usuários podem ser estimulados a contribuir com o processo por meio de dispositivos que registrem comentários, avaliação e encaminhamento da informação recebida (CHOO, 1995).

No contexto de aprendizagem organizacional, a utilização da informação se faz para a construção de conhecimento, num processo social e dinâmico que acontece na troca de interpretações dos indivíduos. Nessa troca, conhecimentos tácitos e explícitos se fundem e criam novos significados que orientam novos padrões de ação organizacional (CHOO, 1995). O discurso inserido no ciclo informacional será utilizado para a construção de novos discursos que

${ }^{4}$ TAYLOR, R. S. Value added processes in information systems. Norwood: Ablex Publishing, 1986. 
podem retratar a realidade para reflexão ou mesmo propiciar modificações no contexto organizacional. A utilização do discurso na gestão se aplica: no gerenciamento de mudanças, na construção de significado, na gestão organizacional, na gestão do conhecimento, na construção de contexto, na metodologia para pesquisas em gerenciamento estratégico, na liderança, na análise do discurso gerencial e na gestão de recursos humanos.

\section{Considerações finais}

A economia do conhecimento necessita de novos paradigmas gerenciais, pois a ideologia do comando e do controle, em que o chefe manda e os subordinados obedecem cegamente, tem apresentado resultados negativos, pois impede que a organização aproveite o conhecimento que subordinados obtêm com a experiência, trazendo insatisfação para as pessoas e prejuízo para a instituição.

Assim, a gestão do conhecimento tem obtido aceitação no ambiente organizacional ao prescrever novas práticas de gestão que aproveitam o ser humano como detentor do mais escasso dos recursos: o conhecimento. Como seres humanos interagem entre si por meio da linguagem, estudos de gestão do conhecimento têm abordado aspectos da linguagem e da comunicação, dos quais a técnica de narrativas é um mecanismo recomendado para diversos propósitos gerenciais.

Sob o prisma da Linguística, a narrativa é um tipo de discurso e a ADC pratica uma abordagem social, o que vai além dos tradicionais estudos formalistas, permitindo que a disciplina investigue a aplicação do discurso em práticas sociais, como por exemplo, das organizações. Existem complexas conexões entre linguagem, aprendizado, conhecimento, sociologia e gestão. Em todas elas, a teoria do discurso tem muito a contribuir.

Uma busca por publicações científicas que relatem o emprego do discurso na gestão organizacional revela várias contribuições significativas, donde se pode inferir que o discurso é um poderoso instrumento para a gestão organizacional. A literatura destaca a importância do discurso na gestão de mudanças, podendo-se deduzir que aprendizagem organizacional e discurso se relacionam. Como a aprendizagem ou mudança dependem da memória, deduz-se, ainda, que a preservação do discurso na memória organizacional favorece os objetivos da própria instituição.

Finalmente, este artigo propõe um processo de gestão informacional para discursos, descrevendo as atividades que devem ser executadas para os inserir no ciclo informacional da organização. Sugere-se para pesquisas futuras a aplicação do processo de gestão informacional para discursos em um estudo de caso que o valide em uma organização. 


\section{Referências}

BAZERMAN, C. Gêneros textuais, tipificação e interação. São Paulo: Cortez, 2005.

BRUSAMOLIN, V. Narrativas de histórias: um estudo preliminar na gestão de projetos de tecnologia da informação. Ciência da Informação. v. 37, n. $1,2008$.

CAMILLE, H. J.; WILLIAN, C. M. Organizational storytelling: it makes sense. Business Horizons, v. 47, n. 4, p. 23-32, jul./ago. 2004.

$\mathrm{CHOO}, \mathrm{C}$. W. Information management for the intelligent organization: roles and implications for the information professions. In: Digital Libraries Conference, mar. 27-28, 1995, Singapore. Disponível em: 〈http://choo.fis.utoronto.ca/fis/respub/dlc95.html >. Acesso em: 4 fev 2009.

CHOU, S. W. Knowledge creation: absorptive capacity, organizational mechanisms, and knowledge storage/retriveal capabilities. Journal of Information Science, v. 31 n. 6, 2005, p. 453-465.

DENNING, S. The leaders guide to storytelling: mastering the art and disciplines of business narrative. Jossey-bass, San Francisco, CA, 2005.

ECHEVERRÍA, R. Ontologia del lenguage. Dólmen Ediciones, Santiago, Chile, 1997.

Reflexão, diálogo e ética nas organizações. Palestra proferida em 21 de maio de 2004, promovida pelo Instituto Ethos de Empresas e Responsabilidade Social no auditório da Serasa, em São Paulo. Disponível em: <http://www1.ethos.org.br/EthosWeb/arquivo/0-A2d0reflexao13WEB.pdf>. Acesso em: 29 jun. 2009.

FAIRCLOUGH, N. Analysing discourse: textual analysis for social research. New York, Routledge, 2003.

Discurso e mudança social. Tradução de Izabel Magalhães. Brasília: Ed. Universidade de Brasília, 2001.

FRANCIS, H. A critical discourse perspective on managers'experience of HRM. In: Qualitative Research in Organizations and Management: an international journal. v. 1, n. 2, 2006.

GARGIULO, T. L. The strategic use of stories in organizational communication and learning. New York, M. E. Shape, 2005.

HACKLEY, C. Silent running: tacit, discursive and psychological aspecs of management in a top UK advertising agency. British Journal of Management. v. 11, n. 3, 2000 .

HARRISON, C.; YOUNG, L. Leadership discourse in action: a textual study of organizational change in a government of Canada department. Journal of Business and Technical Communication. v. 19, n. 1, 2005.

KOFMAN, F. Metamanagement: la nueva con-ciencia de los negocios. Buenos Aires, ed. Granica, 2005.

LE COADIC, Yves-François. A ciência da informação. 2. ed. Brasília. Briquet de Lemos/Livros, 2004.

McGEE, J.; PRUSAK, L. Gerenciamento estratégico da informação. Rio de Janeiro, Ernst\&Young. Campus, 1994.

MOORMAN, C.; MINER, A. S. Organizational improvisation and organizational memory. Academy of Management Review, v. 23, n. 4, 1998, p. 698-723.

107

The impact of organizational memory on new product performance and creativity. Journal of Marketing Research, v. 34, 1997, p. 91 -

PARK, E. P.; BUNN, M. D. Organizational memory: a new perspective on the organizational buying process. The Journal of Business \& Industrial Marketing, 2003.

PHILIPS, N.; LAWRENCE, T.; HARDY, C. Discourse and institutions. Academy of Management Review, v. 29, n. 4, 2004.

PHILLIPS, N. The management of corporate legitimacy: an interpretive structuralist approach. Tese de doutoramento, Universidade de Alberta, Edmonton, 1995.

PHILLIPS, N.; SEWELL, G.; JAYNES, S. Applying critical discourse analysis in strategic management research. Organizational Research Methods. v. 11, n. 4, outubro 2008.

SILLINCE, J. A. A. Organizational context and the discursive construction of organizing. Management Communication Quarterly. v. 20, n. 4, may 2007.

SIMMONS, Annete. The story factor. Cambridge, MA, Basic Books, 2001.

SLATER, S. F.; NARVER, J. C. Market orientation and the learning organization. Journal of Marketing, v. 59, n. 3, 1995, p. 63-74

STEIN, Eric W. Organizational memory: review of concepts and recommendations for management. International Journal of Information Management, v. 15, $\mathrm{n}^{\circ}$ 2, pp. 17-32, 1995.

THOMAS. The Recontextualization of management: a discoursive-based approach to analysing the development of management thinking. Journal of Management Studies. v. 40, n.4, 2003

TRELEAVEN, L.; SYKES, C. Loss of organizational knowledge: from supporting clients to serving head office. Journal of Organizational Change. v. 18, n. 4, 2005

VAARA, E.; KLEYMANN, B.; SERISTÖ, H. Strategies as discoursive constructions: the case of Airline Alliances. Journal of Management Studies. v. 41, n.1, 2004. 